\title{
STUDY ON EARLY-WARNING SYSTEM OF COTTON PRODUCTION IN HEBEI PROVINCE
}

\author{
Runqing Zhang*, Teng Ma \\ School of Economics and Business, Agricultural University of Hebei, Baoding, Hebei \\ Province, P.R China, 071000 \\ * Corresponding author, Address: School of Economics and Business, Agricultural University \\ of Hebei, Baoding, 071000, Hebei Province, P. R. China, Tel: 13012078786, Email: \\ runqingzhang@126.com
}

Abstract: Cotton production plays an important role in Hebei. It straightly influences cotton farmers' life, agricultural production and national economic development as well. In recent years, due to cotton production frequently fluctuating, two situations, "difficult selling cotton" and "difficult buying cotton" have alternately occurred, and brought disadvantages to producers, businesses and national finance. Therefore, it is very crucial to research the early warning of cotton production for solving the problem of cotton production's frequent fluctuation and ensuring the cotton industry's sustainable development. This paper founds a signal lamp model of early warning through employing time-difference correlation analysis method to select early-warning indicators and statistical analysis method associated with empirical analysis to determine early-warning limits. Finally, it not only obtained warning conditions of cotton production from 1993 to 2006 and forecast 2007's condition, but also put forward corresponding countermeasures to prevent cotton production from fluctuating. Furthermore, an early-warning software of cotton production is completed through computer programming on the basis of the early warning model above.

Key words: Cotton Production; Early-warning Model; Early-warning Software

\section{INTRODUCTION}

Hebei is one of largest cotton production provinces in China. In 2006, the actual acreage of cotton planted reached 623,100 hectares, $11.82 \%$ of the

Please use the following format when citing this chapter:

Zhang, R. and Ma, T., 2009, in IFIP International Federation for Information Processing, Volume 294, Computer and Computing Technologies in Agriculture II, Volume 2, eds. D. Li, Z. Chunjiang, (Boston: Springer), pp. 973-980. 
national cotton sown area; and cotton ginned 631,000 tons, about $10 \%$ of the country. Since 1990s, cotton production has shown a significant fluctuation. In 1991, the sown area of cotton arrived at the highest level, 955,200 hectares. But from then on, it dropped down to 1999's 266,600 hectares and after then gradually rose year by year to 2006's 623,100 hectares. Cotton total yield decreased from 570,800 tons of 1990 to 222,600 tons of 1999 and then gradually increased to 2006's 631,000 tons (Hebei Rural Statistical Yearbook, 1991-2007). Cotton production fluctuating not only influences related industries' development but seriously restricts the economy in rural areas and the growth of farmers' income. Therefore, it is very imperative to take research on the early warning of cotton production in order to efficiently monitor and manage cotton production, and further feedback timely abnormal symptoms to relevant departments for making decisions to ensure cotton production normal running.

\section{THE FOUNDATION OF EARLY-WARNING INDICATORS}

\subsection{Selecting the Referential Indicator}

The final result of cotton production is cotton total field. In the whole process of cotton production, when cotton total yield is unsatisfactory, even if most indicators are good, that can't represent cotton production lying in safety. So this paper takes cotton total yield's loop ratio as the referential indicator, which can eliminate its long-term trend and seasonal factor.

\subsection{Selecting and Classifying Other Indicators}

Selecting early-warning indicators should abide by the following principles (Bai Jiyun, 2006):

(1) Synchronousness or antecedence. Early-warning indicators' changes should be coincident with cotton total yield or earlier, and sensitively represent the trend of cotton production.

(2) Relevance. That means indicators should have a direct and inherent relation with cotton production.

(3) Importance. That requires selecting indicators should refer to the agricultural economic theory and can represent cotton production's main aspects.

Employing the method of time-difference correlation analysis to calculate relevant data about cotton production in Hebei from 1990 to 2006, we 
Province

eventually determine 8 early-warning indicators, involving 3 synchronous indicators and 5 antecedent indicators (see Table 1).

Table 1 Results of Selecting Early-warning Indicators

\begin{tabular}{|c|c|c|c|c|c|c|c|}
\hline NO. & Indictors & $\begin{array}{l}\text { 2-Period } \\
\text { Lagging }\end{array}$ & $\begin{array}{l}\text { 1-Period } \\
\text { Lagging }\end{array}$ & $\begin{array}{l}\text { Synch- } \\
\text { ronous } \\
\end{array}$ & $\begin{array}{l}\text { 1-Period } \\
\text { Leading } \\
\end{array}$ & $\begin{array}{l}\text { 2-Period } \\
\text { Leading } \\
\end{array}$ & $\begin{array}{c}\text { Period } \\
\text { Relationship } \\
\end{array}$ \\
\hline 1 & $\begin{array}{l}\text { Loop ratio of cotton unit } \\
\text { yield }\end{array}$ & -0.37 & -0.4 & 0.69 & 0.11 & -0.63 & $\begin{array}{l}\text { Synch } \\
\text { ronous }\end{array}$ \\
\hline 2 & $\begin{array}{l}\text { Loop ratio of cotton sown } \\
\text { area }\end{array}$ & -0.39 & 0.18 & 0.79 & -0.26 & -0.23 & $\begin{array}{l}\text { Synch } \\
\text { ronous }\end{array}$ \\
\hline 3 & $\begin{array}{l}\text { Loop ratio of total output } \\
\text { value of faming, forestry, } \\
\text { animal husbandry and } \\
\text { fishery }\end{array}$ & -0.41 & 0.09 & 0.43 & -0.14 & -0.36 & $\begin{array}{l}\text { Synch } \\
\text { ronous }\end{array}$ \\
\hline 4 & $\begin{array}{l}\text { Ratio of production cost } \\
\text { between grain and cotton }\end{array}$ & -0.33 & -0.45 & 0.032 & 0.46 & -0.21 & $\begin{array}{l}\text { 1-Period } \\
\text { Leading }\end{array}$ \\
\hline 5 & $\begin{array}{l}\text { Loop ratio of cotton } \\
\text { import volume of China }\end{array}$ & 0.1 & 0.09 & 0.3 & 0.41 & -0.2 & $\begin{array}{l}\text { 1-Period } \\
\text { Leading }\end{array}$ \\
\hline 6 & $\begin{array}{l}\text { Loop ratio of household } \\
\text { consumption of Hebei } \\
\text { province }\end{array}$ & -0.18 & 0.3 & 0.17 & -0.09 & -0.33 & $\begin{array}{l}\text { 2-Period } \\
\text { Leading }\end{array}$ \\
\hline 7 & $\begin{array}{l}\text { Loop ratio of per capita } \\
\text { GDP of Hebei }\end{array}$ & -0.11 & -0.03 & 0.03 & 0.07 & -0.39 & $\begin{array}{l}\text { 2-Period } \\
\text { Leading }\end{array}$ \\
\hline 8 & $\begin{array}{l}\text { Loop ratio of fixed assets } \\
\text { investment of Hebei rural } \\
\text { residents }\end{array}$ & -0.5 & -0.03 & 0.42 & -0.3 & -0.81 & $\begin{array}{l}\text { 2-Period } \\
\text { Leading }\end{array}$ \\
\hline
\end{tabular}

\subsection{Determining Every Indicator's Limits}

Determining early-warning limits is a key step to set up an early warning model. What kind of warning condition will be forecast much depends on how early-warning limits are determined.

First of all, considering conditions of cotton production in past 16 years, the paper classifies them into 5 sorts - "Severely Cold", "Slightly Cold", "Normal", "Slightly Hot" and "Severely Hot", in which " Severely Cold" means cotton production in extreme depression and it is quite difficult to recover; "Slightly Cold" means cotton production may become normal or depressive in the near future; "Normal" means cotton production in a healthy condition and cotton market is running well; "Slightly Hot" means cotton production runs still stably with the output growing a little fast and may turn to "Severely Hot" or "Normal" in a short period; "Severely Hot" means 
cotton output grows so fast that supply and demand are in extreme imbalance, together with the common phenomenon of being difficult to sell cotton.

Secondly, determining early-warning indicator's limits should follow two principles below: For one thing, it should be based on every indicator's historical data to set the centerline of fluctuation as the normal field's center and then according to the probability that indicators appear in different fields to get the basic limits - mathematic critical points. For another, when data are not enough or it lies in a long-term abnormal condition, unsuitable values must be eliminated by relevant theories and empirical judgments.

Concrete measures are as follows: First, make "O', green lamp, represent "Normal". It should be in the middle and its probability is between $40 \%$ and $60 \%$. Here, we choose the probability of $50 \%$. Second, make "O", red lamp and "O", blue lamp respectively represent two extreme fields "Severely Hot" and "Severely Cold", and their probabilities are generally fixed $10 \%$ each. Last, " ", yellow lamp and " " light blue lamp are used to represent "Slightly Hot" and "Slightly Cold", two relative stable fields. Each of their probabilities is $15 \%$, a little more than the extreme fields' (Gong Yingying, 2005).

Every early-warning indicator's limits are as follows:

Table 2 Limits of Early-warning Indicators

\begin{tabular}{|c|c|c|c|c|c|}
\hline Indicators & Blue & Light Blue & Green & Yellow & Red \\
\hline Loop ratio of cotton total yield & $0 \sim 0.78$ & $0.78 \sim 1.05$ & $1.05 \sim 1.33$ & $1.33 \sim 2.03$ & $2.03 \sim \infty$ \\
\hline Loop ratio of cotton sown area & $0 \sim 0.6$ & $0.6 \sim 0.85$ & $0.85 \sim 1.24$ & $1.24 \sim 1.39$ & $1.39 \sim \infty$ \\
\hline Loop ratio of cotton unit yield & $0 \sim 0.72$ & $0.72 \sim 0.98$ & $0.98 \sim 1.16$ & $1.16 \sim 1.42$ & $1.42 \sim \infty$ \\
\hline $\begin{array}{l}\text { Loop ratio of total output value of faming, } \\
\text { forestry, animal husbandry and fishery }\end{array}$ & $0 \sim 1.02$ & $1.02 \sim 1.08$ & $1.08 \sim 1.22$ & $1.22 \sim 1.49$ & $1.49 \sim \infty$ \\
\hline $\begin{array}{l}\text { Ratio of production cost between grain and } \\
\text { cotton }\end{array}$ & $\infty \sim 1.64$ & $1.64 \sim 1.47$ & $1.47 \sim 1.30$ & $1.30 \sim 1.10$ & $1.10 \sim 0$ \\
\hline Loop ratio of cotton import volume of China & $0 \sim 0.45$ & $0.45 \sim 1.26$ & $1.26 \sim 2.83$ & $2.83 \sim 5.39$ & $5.39 \sim \infty$ \\
\hline $\begin{array}{l}\text { Loop ratio of household consumption of } \\
\text { Hebei province }\end{array}$ & $0 \sim 1.04$ & $1.04 \sim 1.09$ & $1.09 \sim 1.14$ & $1.14 \sim 1.24$ & $1.24 \sim \infty$ \\
\hline Loop ratio of per capita GDP of Hebei & $0 \sim 1.07$ & $1.07 \sim 1.14$ & $1.14 \sim 1.23$ & $1.23 \sim 1.31$ & $1.31 \sim \infty$ \\
\hline $\begin{array}{l}\text { Loop ratio of fixed assets investment of Hebei } \\
\text { rural residents }\end{array}$ & $0 \sim 0.88$ & $0.88 \sim 1.03$ & $1.03 \sim 1.29$ & $1.29 \sim 1.74$ & $1.74 \sim \infty$ \\
\hline States & Severely Cold & Slightly Cold & Normal & Slightly Hot & Severely Hot \\
\hline
\end{tabular}

\subsection{Determining the Composite Early-warning Limits}

After getting each indicator's limits, we need to fix the composite earlywarning limits. Firstly, we set every signal different scores. Here, "Red Lamp" is given 5 scores, "Yellow Lamp" 4 scores, "Green Lamp" 3 scores, "Light Blue Lamp" 2 scores and "Blue Lamp" only 1 score. And then, we make 36 scores, $80 \%$ of the full scores calculated by $5 \times M$ ( $M$ is the number of indicators, and here it is 9) as the boundary between "Red Lamp" and "Yellow Lamp"; 31.5 scores, 70\%, and 22.5 scores, 50\% respectively as 
two boundaries between "Yellow Lamp" and "Green Lamp" and between "Green Lamp" and "Light Blue Lamp"; 18 scores, 40\% as the boundary between "Light Blue Lamp" and "Blue Lamp". Table 3 below shows each year's early-warning condition from 1993 to 2006.

Table 3 Cotton Production State 1993-2006 in Hebei Province

\begin{tabular}{|c|c|c|c|c|c|c|c|c|c|c|c|}
\hline Year & $\begin{array}{l}\text { Loop ratio } \\
\text { of cotton } \\
\text { total yield }\end{array}$ & $\begin{array}{l}\text { Loop ratio } \\
\text { of cotton } \\
\text { sown area }\end{array}$ & $\begin{array}{l}\text { Loop ratio } \\
\text { of cotton } \\
\text { unit yield }\end{array}$ & $\begin{array}{c}\text { Loop ratio } \\
\text { of total } \\
\text { output } \\
\text { value of } \\
\text { faming, } \\
\text { forestry, } \\
\text { animal } \\
\text { husbandry } \\
\text { and } \\
\text { fishery }\end{array}$ & $\begin{array}{l}\text { Ratio of } \\
\text { production } \\
\text { cost } \\
\text { between } \\
\text { grain and } \\
\text { cotton }\end{array}$ & $\begin{array}{l}\text { Loop ratio } \\
\text { of cotton } \\
\text { import } \\
\text { volume of } \\
\text { China }\end{array}$ & $\begin{array}{l}\text { Loop ratio } \\
\text { of } \\
\text { household } \\
\text { consumpti } \\
\text { on of } \\
\text { Hebei } \\
\text { province }\end{array}$ & $\begin{array}{l}\text { Loop ratio } \\
\text { of per } \\
\text { capita } \\
\text { GDP of } \\
\text { Hebei }\end{array}$ & $\begin{array}{l}\text { Loop ratio } \\
\text { of fixed } \\
\text { assets } \\
\text { investmen } \\
\text { t of Hebei } \\
\text { rural } \\
\text { residents }\end{array}$ & $\begin{array}{l}\text { Total } \\
\text { Points }\end{array}$ & State \\
\hline 1993 & 1 & 1 & 3 & 3 & 3 & 1 & 2 & 3 & 5 & 22 & $\overline{\text { Light Blue }}$ \\
\hline 1994 & 4 & 4 & 5 & 5 & 5 & 4 & 3 & 3 & 1 & 34 & Yellow \\
\hline 1995 & 2 & 3 & 2 & 4 & 4 & 4 & 4 & 4 & 3 & 30 & Green \\
\hline 1996 & 1 & 2 & 3 & 3 & 3 & 2 & 4 & 4 & 4 & 26 & Green \\
\hline 1997 & 2 & 3 & 3 & 3 & 3 & 2 & 5 & 4 & 4 & 29 & Green \\
\hline 1998 & 3 & 2 & 4 & 2 & 3 & 2 & 3 & 3 & 3 & 25 & Green \\
\hline 1999 & 2 & 2 & 2 & 1 & 3 & 1 & 3 & 2 & 4 & 20 & Light Blue \\
\hline 2000 & 4 & 3 & 4 & 1 & 4 & 1 & 1 & 1 & 2 & 21 & Light Blue \\
\hline 2001 & 4 & 4 & 3 & 3 & 4 & 3 & 2 & 1 & 2 & 26 & Green \\
\hline 2002 & 2 & 3 & 2 & 2 & 2 & 3 & 3 & 2 & 3 & 22 & Light Blue \\
\hline 2003 & 3 & 4 & 2 & 3 & 2 & 5 & 3 & 2 & 3 & 27 & Green \\
\hline 2004 & 3 & 3 & 3 & 3 & 1 & 3 & 3 & 2 & 2 & 23 & Green \\
\hline 2005 & 2 & 3 & 2 & 3 & 2 & 2 & 3 & 3 & 2 & 22 & Light Blue \\
\hline 2006 & 3 & 3 & 3 & 2 & 2 & 3 & 3 & 4 & 3 & 26 & Green \\
\hline
\end{tabular}

Note: Because leading-2 periods indicators' loop ratios are involved from 1991 the early-warning condition can only be given from 1993.

\section{DEVELOPING EARLY-WARNING SOFTWARE OF COTTON PRODUCTION}

After analyzing relevant theoretical issues on the early warning of cotton production, this chapter will introduce the development of an early-warning software to operate corresponding functions.

\subsection{General Design of Software}

Java and SQL Sever 2000 are used to compile this software together. Java is an object-oriented programming language with features of safety, simplicity, easy usage and cross-platform. Microsoft SQL Server 2000 is a comprehensive, integrated data management and analysis software that enables organizations to reliably manage mission-critical information and 
confidently run increasingly complex business applications. At the beginning of developing software, the object-oriented programming method and form technique of Java is used to generate GUI-Graphics User Interface. All of these make the main menu very friendly and easy to operate (Zhou Haijun, 2006).

This software provides the following 4 functions: (1) User Management—add users, delete users and reset password (2) Data management- —input and edit every indicator's data and calculate their loop rates for eliminating the season factor of time series (3) Graphics analysis - - show curve diagrams of cotton total yield and sown area (4) Early-warning signal system analyze processed data and display their individual early-warning signals and the composite condition.

\subsection{Software Introduction}

On the basis of the above explanation of the software's design and function, we develop the cotton production early-warning system by computer software programming.

Log on the software and enter the main interface (See Fig.1). Four functions of the main interface are shown, consisting of "Indicator", "Early Warning", "System Management" and "Help".

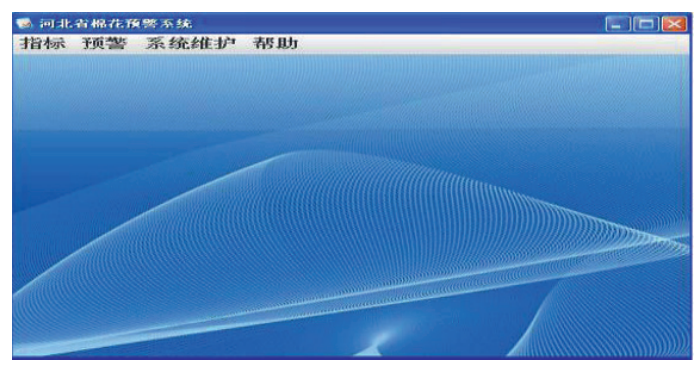

Fig.1 Main Interface of Early-Warning Software

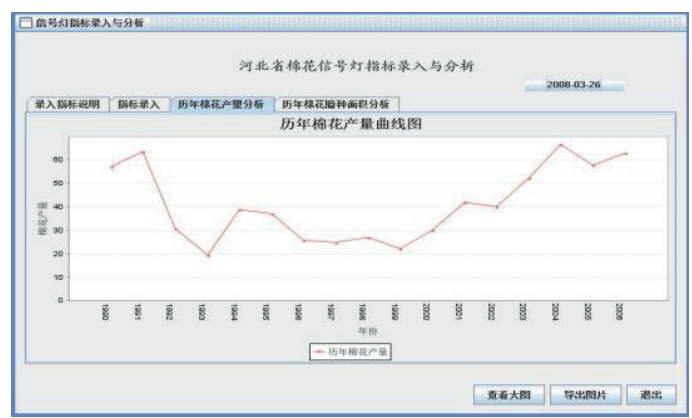

Fig.2 Analysis of Cotton Total Yield 
After analyzing indicators' data inputted, Fig.2 displays the drawing function of the software on cotton total yield.

Finally, we can easily and straightly get early-warning results on cotton production from 1993 to 2006, shown in Fig.3.

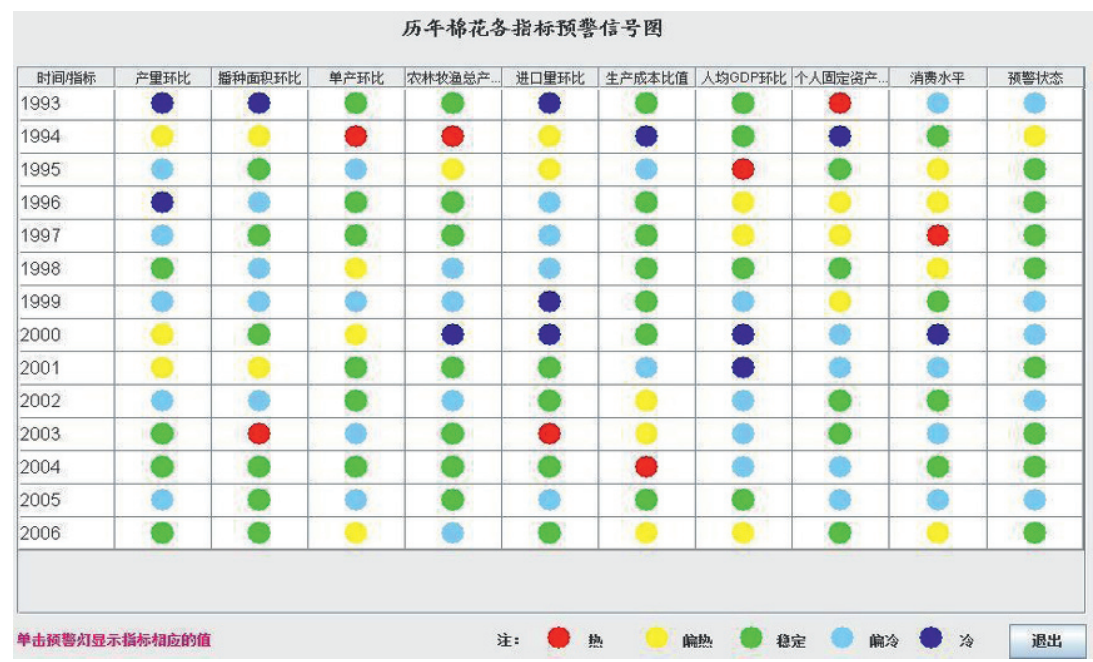

Fig. 3 Signal Chart of Early-Warning Software

\section{CONCLUSION}

From the investigation in early 2007 by Hebei Survey Organization of National Bureau of Statistics, 2007cotton production in Hebei Province shows three characters — all of cotton sown area, unit yield and total yield will have some increases compared with 2006, among which cotton sown area is 623,100 hectares, unit yield $1018.5 \mathrm{~kg} /$ ha and total field expected to be 661,000 tons. On the basis of 3 synchronous indicators' values and 5 indicators with leading one or two period, we can infer that the whole scores of 8 indicators added is 22 scores when neglecting the indicator of total output value of faming, forestry, animal husbandry and fishery. Because its score scale is 1 to 5 , the whole score scale in 2007 can be inferred to be 23 to 27, embraced in the range of "Green Lamp", 22.5 to 31.5. Thus, we can draw a conclusion that the early-warning condition of cotton production in 2007 will lie in the field of "Green Lamp", being normal.

In accordance with cotton production's features, we should take corresponding countermeasures for different early-warning conditions (Tan Yanwen, 2005). 
(1) Normal. If the early-warning result is cotton production in a normal condition, what we should do is to steady cotton production, deal well with breeding, marketing, producing, circulating and processing and so forth, in order to raise the whole competent ability of cotton industry, which is a long-term task.

(2) Slightly or Severely Hot. If the result is cotton production in slightly or severely hot condition, it generally means supply much exceeds demand so that sale price of cotton drops greatly. When it happens, we should purchase a large number of cotton to raise the sale price for preventing the phenomenon of "Cheap price of crops will cut down farmers' income". At the same time, it is also necessary to reduce the amount of both imported cotton and the transferred from other provinces, seize this opportunity to replace cotton stock, whose cost is lower. At last, we should make use of the timely price guidance to adjust cultivation and production of cotton in the coming year.

(3) Slightly or Severely Cold. If the result is cotton production in slightly or severely cold condition, it generally means supply is less than demand and the sale price will climb up. The countermeasures we should take are to release the national cotton stock as soon as possible to stabilize prices, speed up importing or transferring cotton from other provinces to make up the market difference between supply and demand. In the long run, however, the main countermeasure is to stably improve the capacity of cotton production for guaranteeing the cotton supply.

All in all, the above are just some general countermeasures under different early-warning conditions. In practice, we should inquire into all kinds of conditions, find out the main reason and then take corresponding measures. Furthermore, sometimes it is necessary to make a comprehensive analysis and diagnosis for early-warning conditions.

\section{REFERENCES}

Bai Jiyun. The Forecast and Early Warning Research and Concrete Evidence Analysis about Production of Soybean in Hei Longjiang Province, Northeast Agricultural University, 2006 Gong Yingying. Research on Economic Supervising and Early Warning System Based on Prosperity Index, Wuhan University of Technology, 2005

Hebei Economic Yearbook 1991-2006. Beijing: China Statistics Publishing House, 2007

Hebei Rural Statistical Yearbook 1991-2007. Beijing: China Statistics Publishing House, 2007

Tan Yanwen. Study on Fluctuation of Cotton Production in China. Beijing: China Economy Press, 2005

Zhou Haijun. Java Programming. Beijing: China Railway Publishing House, 2006 